\title{
ALGUNAS REFLEXIONES EN TORNO A LAS IDEAS DE RICARDO NASSIF Y LA PEDAGOGÍA
}

María E. Del Valle Mejías: UNIMET (VENEZUELA)

\section{"La Educación es la acción de un hombre cabal sobre un hombre total" Nassif.}

\section{Introducción}

El epígrafe con el que se comienza esta breve reflexión sirve de introducción a la visión particular que el académico Ricardo Nassif tenía de la pedagogía y en consecuencia de la educación. Para él existen condiciones para educar y existen condiciones para aprender. Sólo un hombre cabal puede llevarla a acabo y solo un hombre total puede aprovecharla.

Estas líneas han sido definidas como "algunas reflexiones" con toda intencionalidad. Lo que se pretende a través de este ensayo, no es abarcar la totalidad de la abundante producción de Nassif sobre la Pedagogía como ciencia, empresa que sería atrevida e imprudente. Lo que se persigue es aproximarnos a la comprensión de sus producciones, las ideas más importantes que de ella pueden extraerse y el impacto que las mismas tuvieron y tienen en el campo de la pedagogía y la educación.

Primeramente, es importante detenerse en las características del personaje. Ricardo Nassif nació el 28 de mayo de 1924, egresa de la Facultad de Humanidades y Educación de la Universidad Nacional de la Plata- Argentina. Allí trabaja como profesor de la Facultad y como Director del Instituto de Pedagogía y fallece el 30 de Noviembre de 1984. 
Su obra como es sabido es reconocida como una de las bases sobre las cuales el concepto, la estructura, la autonomía y las partes de la pedagogía se construyen.

Según Nassif (1984) la pedagogía se relaciona con otras ciencias y ciencias:

a) La pedagogía es filosofía, actitud de pensadores idealistas como GIOVANNI GENTILE, WINEKEN y LOMBARDO RADICE.

b) La pedagogía depende de la filosofía.

c) La pedagogía es floración ó sublimación de la filosofía, actitud de corriente científica espiritual de DILTHEY.

d) La filosofía es una de las fuentes de estudio de la educación $p$ 101.

Educar, enseñar, aprender, practicar la pedagogía es definido por el autor como un proceso complejo en el cual se conjugan muchos factores. La filosofía en la que sin duda se dejan ver elementos morales y de formación del docente, la visión del proceso educativo, su concepción de la enseñanza, del alumno y del papel que él se atribuye a sí mismo son elementos a considerar.

Filosofía, Educación, Pedagogía, cada una de ellas definidas desde su propia perspectiva. Esa forma de asumir la pedagogía y en general el proceso pedagógico lo distinguen. Pedagogía por ejemplo, es definida por el autor primero Etimológicamente como pedagogía (del griego: paidós = niño, y de agogía = conducción) equivale a conducción del niño. En sus orígenes el pedagogo (paidagogos) fue el esclavo que cuidaba de los niños y los acompañaba a la escuela Mucho más tarde, en los siglos XVII y XVIII, todavía se empleaba ese nombre para los preceptores de los hijos de familias acomodadas $\mathrm{p} 3$.

Sin embargo, esta concepción no lo convencía ya que parecía plantear la pedagogía como un proceso que viene "desde fuera" o lo que los especialistas denominaron un modelo "intervencionista" y aunque no negaba la realidad de que todo lo que se encuentra en el exterior nos educa, el papel del pedagogo y del estudiante va mucho más allá de solo recibir la influencia del exterior y en el caso del docente suministrar la información.

Nassif (1965), nos atreveríamos a afirmar que ya señalaba el agotamiento de los modelos educativos vigentes y reclama cambios curriculares que formen un individuo que responda a las necesidades de la sociedad. Ya reclamaba la necesidad de una pedagogía crítica que contribuya a la elevación del hombre. 
Construir una nueva educación, una nueva pedagogía. Pareciera que sus palabras escritas y acompañadas con la práctica en momento histórico de la educación latinoamericana, tuvieran hoy total vigencia, son los mismos problemas, las mismas limitaciones a las que 23 años después de haberlas escrito y denunciado persiguieran a la práctica educativa como una pesadilla recurrente. A este respecto afirma Nassif (1984): "Una educación que según los casos, contribuya a crear las condiciones para la comprensión del funcionamiento de la sociedad, o si se trata de transformarla, que lleve a su cuestionamiento pero proporcionando a los hombres los medios para producir su transformación"

Se trata entonces, según el autor de una educación para cada caso, lo cual erradicaría la práctica común de copiar de manera ingenua o cómoda, como prefiera verse, modelos curriculares exitosos en otras latitudes y generar los propios de acuerdo con las propias necesidades. Además, le otorga al estudiante la capacidad no solo de repetir lo que le enseña su profesor sino de generar respuestas a las necesidades de la sociedad y dotándolo del poder para transformarla.

No niega la efectividad de lo que llamaba hetero-educación, actitud que además de absurda sería inútil, sino que nos invita a formar al estudiante para defenderse en esos ambientes. Por otro lado, ya anticipaba lo que hoy denominan los especialistas, "Ios espacios no convencionales de aprendizaje" el lo denominaba educación cósmica: inconciente, asistémica, natural, espontánea (Nassif 1980)

Recuerda la necesidad de vincular la práctica con la teoría, la norma con la ley, la experiencia con la doctrina, destacando que muchas veces la teoría se queda en los libros y allí de nada sirve, que las leyes deben responder al hombre y no al revés y que las doctrinas como las buenas máquinas se prueban en el campo de trabajo, teniendo en cuenta además, que las realidades cambian vertiginosamente y que si no cambiamos con ellas, las mismas caducan y de nada sirven, a decir del autor "la práctica alimenta a la teoría y la teoría debe volverse sobre la práctica para enriquecerla" p 67.

Se pregunta: ¿qué se enseña?, ¿para qué se enseña? ¿Cómo se enseña? ¿Cuándo se enseña? ¿Para qué?, como coordenadas en un viaje que guían el proceso pedagógico para que tenga un destino seguro, pertinente y productivo.

Finalmente, la concepción de la pedagogía como "arte", es más que una metáfora del proceso. Todo un compromiso cargado de complejidades, primero porque no es un arte en solitario (aunque así 
pareciera plantearlo), donde el profesor cree que lo hace de manera unidireccional, segundo porque son dos artistas: el profesor y el alumno quienes al final deben haber construido esa obra de arte que a ambos debe edificar.

Esa obra de arte requiere de la técnica definida por el Diccionario de la Real Academia como:

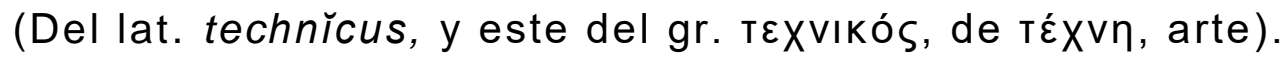

1.adj. Perteneciente o relativo a las aplicaciones de las ciencias y las artes.

2.adj. Dicho de una palabra o de una expresión: Empleada exclusivamente, y con sentido distinto del vulgar, en el lenguaje propio de un arte, ciencia, oficio, etc.

3.m. y f. Persona que posee los conocimientos especiales de una ciencia o arte.

5.f. Conjunto de procedimientos y recursos de que se sirve una ciencia o un arte.

6.f. Pericia o habilidad para usar de esos procedimientos y recursos.

7.f. Habilidad para ejecutar cualquier cosa, o para conseguir algo.

Luego de revisar estas definiciones podría afirmarse, que la técnica es "saber hacer", en este caso saber enseñar, proceso que al final no solo dependerá de las experticias del profesor sino de la disposición que tenga el estudiante para aprender.

Finalmente, el aprender es una empresa solitaria, al final por muy bueno que sea el profesor, si el alumno no está comprometido con su proceso de formación, de poco valdrán todas las experticias del docente. Podríamos definir al proceso pedagógico, como un baile, hermoso, estructurado, sistémico, planificado, pero a la vez espontáneo, creativo, original pero, en el que bailan dos comprometidos de igual manera, en disfrutar "el baile hermoso de enseñar y aprender".

\section{Referencias}

DICCIONARIO DE LA REAL ACADEMIA. Vigésima Segunda edición. Disponible en www.drae.es 
ALGUNAS REFLEXIONES EN TORNO A LAS IDEAS DE RICARDO NASSIF Y LA PEDAGOGÍA

NASSIF, R. (1965) Pedagogía de nuestro tiempo. Editorial Kapelusz. Buenos Aires, Argentina.

NASSIF, R. (1978) Pedagogía general. Editorial Kapelusz. Buenos Aires. Argentina.

NASSIF, R. (1980) Teorías de la educación CINCE-Kapelusz, Buenos Aires, Argentina.

NASSIF, R. (1984) Tendencias pedagógicas en América Latina (19601980). Sistema Educativo en América Latina. Editorial Kapelusz. Buenos Aires. Argentina. 